\title{
EFEKTIVITAS MENGKONSUMSI BUAH SIWALAN DAN NATA DE COCO TERHADAP NILAI DEBRIS INDEKS PADA SISWA KELAS IV SD NGESREP 02 SEMARANG
}

\author{
Erni Mardiati $^{\bowtie 1}$, Aning Susilowati ${ }^{2}$, Diyah Fatmasari ${ }^{3}$, Irma HYSiregar ${ }^{4}$
}

\begin{abstract}
ABSTRAK
Siwalan adalah tanaman berumah dua, pada satu pohon hanya terdapat satu jenis bunga yaitu jantan atau betina. Daging buah siwalan muda enak dimakan dan airnya berasa manis. Nata de coco adalah jenis komponen minuman yang merupakan senyawa selulosa (dietary fiber), yang dihasilkan dari air kelapa melalui proses fermentasi, yang melibatkan jasad renik (mikrobia). Debris indeks adalah skor/ nilai pada endapan lunak yang terjadi karena adanya sisa makanan yang melekat pada gigi penentu. Tujuan penelitian ini adalah untuk mengetahui efektivitas mengkonsumsi buah siwalan dan nata de coco terhadap nilai debris indeks pada siswa kelas IV SD Ngesrep 02 Semarang.

Metode yang digunakan dalam penelitian ini adalah quasy experiment atau sering disebut dengan eksperimen semu. Rancangan penelitian ini menggunakan 2 kelompok sampel dengan melakukan pengukuran observasi awal dan observasi akhir. Populasi dalam penelitian ini adalah siswa kelas IV SD Ngesrep 02 Semarang dengan jumlah siswa 38 anak. Analisa menggunakandeskriptif kuantitatif dengan metode tabulasi untuk mengetahui efektivitas mengkonsumsi buah siwalan dan nata de cocoterhadap penurunan nilai DI.

Hasil penelitian menunjukkan rata-rata debris indeks sebelum mengkonsumsi buah siwalan adalah 1,13 dan sesudah mengkonsumsi buah siwalan adalah 0,43 sehingga memiliki selisih sebesar 0,7. Sedangkan rata-rata debris indeks sebelum mengkonsumsi nata de coco adalah 1,1dan sesudah mengkonsumsi nata de coco adalah 0,6 sehingga memiliki selisih sebesar 0,5. Hal ini menunjukkan bahwa buah siwalan cenderung lebih efektif menurunkan debris indeks dibandingkan dengan nata de coco dengan perbedaan yang tidak terlalu signifikan.
\end{abstract}

Kata Kunci : Siwalan, Nata de coco, Debris Indeks

\begin{abstract}
Siwalan was two plants, on one tree there is only one type of flower is male or female. Young palm fruit flesh is good to eat and the water taste sweet. Nata de coco is a type of beverage component which is a compound cellulose (dietary fiber), which is produced from coconut water through a fermentation process, which involves microorganisms (microbes). Debris index is a score on soft sediment that occurs because of the leftovers are attached to the teeth determinants. The purpose of this study was to examine the effectiveness of consuming fruit and nata de coco palm against the value of the index debris on fourth grade students Ngesrep 02 Semarang.

The method used in this study is quasy experiment or often referred to as a quasi-experimental. The design of this study using two groups of samples by measuring the initial observation and final observation. The population in this study is a fourth grade student Ngesrep 02 Semarang with the number of students 38 children. Menggunakan deskriptif quantitative analysis with tabulation method to determine the effectiveness of palm fruit consumption and nata de cocoterhadap impairment DI.

Results showed the averages index debris before consuming palm fruit was $1.13 \%$ and after consuming palm fruit was 0.43 so it has a difference of 0.7. While the averages index debris before taking nata de coco is $1,1 \%$ after consuming nata de coco is 0.6 so it has a difference of 0.5 . This shows that palm fruit debris tends to be more effective in lowering the index compared with nata de coco with the difference that was not significant.
\end{abstract}

Keywords : Siwalan, Nata de coco, Debris Index

\footnotetext{
$\overline{1,2,3,4)}$ Dosen Jurusan Keperawatan Gigi Poltekkes Kemenkes Semarang

$凶$ : erni.mardiati28@gmail.com
} 


\section{PENDAHULUAN}

Debris adalah sisa-sisa makanan yang berada di dalam mulut dan menempel pada permukaan gigi atau di sela-sela gigi. Debris dapat dihilangkan dengan cara menyikat gigi dan berkumur air (Sariningsih,2012). Alternatif lain untuk menurunkan angka debris yaitu dengan mengkonsumsi buah seperti buah siwalan yang aman bagi gigi karena buah dan sayur mengandung serat seperti misalkan nata de coco yang sangat efektif berfungsi sebagai pembersih gigi secara alamiah (self cleansing) (Darmawan,2007). Pada penelitian ini variabel yang digunakan adalah makanan berserat seperti halnya buah siwalan dan nata de coco. Buah siwalan berbentuk bulat, sebesar bola sepak takraw, di dalam buah terdapat biji dan serabut mengandung air. Pada setiap buah memiliki 1-3 biji, isi berwarna putih, mirip daging buah kelapa. Daging buah yang tua, berwarna kekuningan dan berserat, dapat dimakan segara ataupun dimasak terlebih dahulu. Cairan kekuningan ini yang diambil untuk dijadikan campuran panganan atau kue-kue atau untuk dibuat menjadi selai(Zumiati, 2009).

Nata de coco adalah jenis komponen minuman yang merupakan senyawa selulosa (dietary fiber), yang dihasilkan dari air kelapa melalui proses fermentasi, yang melibatkan jasad renik (mikroba), yang selanjutnya dikenal sebagai bibit nata de coco. Nata de cocosangat baik apabila diolah menjadi makanan atau pun miuman penyegar, karena nata de coco mengandung serat pangan (Pambayun, 2006).

Berdasarkan studi pendahuluan diketahui bahwa siswa SD Ngesrep 02 Semarang mempunyai kebiasaan mengkonsumsi berbagai macam jajanan, diantara jajanan tersebut ada yang termasuk jenis makanan kariogenik, makanan melekat dan bertekstur padat. Hal ini yang menyebabkan kondisi kebersihan gigi dan mulut anak yang sangat bervariasi. Selain itu, siswa-siswa ini sangat kooperatif terhadap kegiatan pelayanan kesehatan gigi terbukti saat praktek kerja lapangan di SD Ngesrep 02 .

Populasi dalam penelitian adalah siswa kelas IV SD Ngesrep 02 dengan jumlah siswa 38 anak. Sehingga sampel adalah total populasi

Rancangan dengan quasy experiment (eksperiment semu) penelitian ini menggunakan 2 kelompok sampel dengan melakukan pengukuran observasi awal yaitu mengukur keadaan debris indeks sebelum dilakukan penelitian (mengkonsumsi siwalan dan nata de coco) dan dilakukan observasi akhir mengukur keadaan debris Indeks sesudah dilakukan perlakuan (mengkonsumsi siwalan dan nata de coco).

Rancangan Penelitian :

Keterangan:

$$
\begin{aligned}
& \mathrm{O}_{1} \longrightarrow \mathrm{X}_{1} \longrightarrow \mathrm{O}_{2} \\
& \mathrm{O}_{3} \longrightarrow \mathrm{X}_{2} \longrightarrow \mathrm{O}_{4}
\end{aligned}
$$

$\mathrm{O}_{1}$ : Observasi / pemeriksaan nilai debris indeks yang dilakukan sebelum mengkonsumsi buahsiwalan.

$\mathrm{O}_{2}$ : Observasi / pemeriksaan nilai debris indeks yang dilakukan sesudah mengkonsumsi buah siwalan.

$\mathrm{O}_{3}$ : Observasi / pemeriksaan nilai debris indeks yang dilakukan sebelum mengkonsumsi nata de coco.

$\mathrm{O}_{4}$ : Observasi / pemeriksaan nilai debris indeks yang dilakukan sesudah mengkonsumsi nata de coco.

$\mathrm{X}_{1}$ : Perlakuan mengkonsumsi buah siwalan.

$\mathrm{X}_{2}$ : Perlakuan mengkonsumsi nata de coco.

\section{HASIL DAN PEMBAHASAN}

Tabel 1. Distribusi Frekuensi Kategori Debris Indeks Sebelum dan Sesudah Mengkonsumsi Buah Siwalan Pada Kelas IV SD Ngesrep 02 Semarang

\begin{tabular}{ccccc}
\hline \multirow{2}{*}{ Debris Indeks } & \multicolumn{2}{c}{ Sebelum } & \multicolumn{2}{c}{ Sesudah } \\
\cline { 2 - 5 } & Frekuensi & $\%$ & Frekuensi & $\%$ \\
\hline Baik $(0-0,6)$ & 5 & 26,3 & 16 & 84,3 \\
\hline $\begin{array}{c}\text { Sedang }(0,7- \\
1,8)\end{array}$ & 11 & 58 & 3 & 15,7 \\
\hline Buruk $(1,9-3,0)$ & 3 & 15,7 & 0 & 0 \\
\hline Jumlah & 19 & 100 & 19 & 100 \\
\hline Rata - rata & 1,13 & & 0,43 & \\
\hline
\end{tabular}


Tabel diatas dapat dilihat bahwa terdapat perubahan nilai debris indeks antara sebelum dan sesudah mengkonsum sibuah siwalan. Sebelum mengkonsumsi buah siwalan, debris indeks dengan kategori baik sebanyak 5 responden dan sesudah mengkonsumsi buah siwalan ada peningkatan menjadi 16 responden. Sedangkan debris indeks sebelum mengkonsumsi buah siwalan dengan kategori buruk sebanyak 3 responden dan sesudah mengkonsumsi buah siwalan tidak ada responden dengan kategori buruk.

Tabel 2. Distribusi Frekuensi Kategori Debris Indeks Sebelum dan Sesudah Mengkonsumsi Nata de Coco Pada Siswa Kelas IV SD Ngesrep 02 Semarang

\begin{tabular}{ccccc}
\hline \multirow{2}{*}{ Debris Indeks } & \multicolumn{2}{c}{ Sebelum } & \multicolumn{2}{c}{ Sesudah } \\
\cline { 2 - 5 } & Frekuensi & $\%$ & Frekuensi & $\%$ \\
\hline Baik $(0-0,6)$ & 7 & 37 & 12 & 63 \\
\hline Sedang $(0,7-1,8)$ & 10 & 53 & 7 & 37 \\
\hline Buruk $(1,9-3,0)$ & 2 & 10 & 0 & 0 \\
\hline Jumlah & 19 & 100 & 19 & 100 \\
\hline Rata - rata & 1,1 & \multicolumn{3}{c}{0,6} \\
\hline
\end{tabular}

Tabel diatas dapat dilihat bahwa terdapat penurunan nilai debris indeks sebelum dan sesudah mengkonsumsi nata de coco. Sebelum mengkonsumsi nata de coco frekuensi kategori debris indeks terbesar adalah kategori sedang sebanyak 10 responden. Sedangkan sesudah mengkonsumsi nata de coco frekuensi kategori debris indeks terbesar adalah kategori baik sebanyak 12 responden dan frekuensi kategori debris terkecilnya adalah kategori buruk dengan 0 responden.

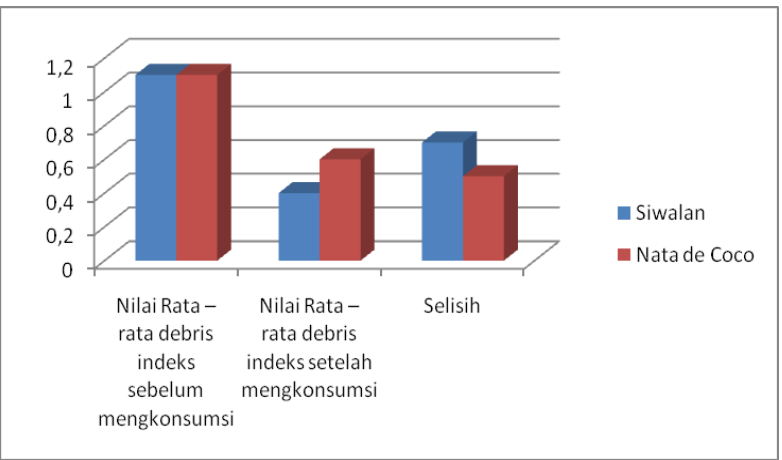

Gambar 1. Grafik Distribusi Frekuensi kategori Debris Indeks Sebelum dan Sesudah Mengkonsumsi Buah Siwalan dan Nata De Coco Pada Siswa Kelas IV SD Ngesrep 02 Semarang
Tabel dan gambar diatas menunjukkan rata-rata debris indeks sebelum mengkonsumsi buah siwalan adalah 1,13 dan sesudah mengkonsumsi buah siwalan adalah 0,43 sehingga memiliki selisih sebesar 0,7. Sedangkan rata-rata debris indeks sebelum mengkonsumsi nata de coco adalah 1,1 dan sesudah mengkonsumsi nata de coco adalah 0,6 sehingga memiliki selisih sebesar 0,5

Hasil Penelitian mengenai efektifitas mengkonsumsi buah siwalan dan nata de coco terhadap nilai debris indeks pada siswa kelas IV SD Ngesrep 02 Semarang, didapatkan frekuensi debris indeks responden sebelum mengkonsumsi buah siwalan pada kategori baik sebanyak 5 responden, kategori sedang sebanyak 11 responden dan kategori buruk sebanyak 3 responden dan setelah mengkonsumsi buah siwalan meningkat menjadi 16 responden kategori baik dan 3 responden kategori sedang. Hal ini menunjukkan bahwa terjadi penurunan debris indeks setelah mengkonsumsi buah siwalan. Penurunan debris indeks ini disebabkan karena buah siwalan banyak mengandung air sebesar $85 \%$ dan serat sehingga memicu terjadinya pembersihan gigi yang alami (self cleansing). Seperti yang telah dikemukakan oleh Darmawan (2007) buah dan sayur yang mengandung serat sangat efektif berfungsi sebagai pembersih gigi secara alamiah (self cleansing).

Debris indeks responden sebelum mengkonsumsi nata de coco didapatkan 7 responden kategori baik, 10 responden kategori sedang, 2 responden kategori buruk dan setelah mengkonsumsi nata de coco meningkat menjadi 12 responden kategori baik dan 7 responden kategori sedang. Hal ini menunjukkan telah terjadi penurunan debris indeks setelah mengkonsumsi nata de coco. Nata de coco memiliki tekstur ysng sukulen (mengandung banyak air sebesar 91,50\%) dan berserat. Nata de coco dapat digunakan sebagai pencuci mulut pengganti buah. Tekstur yang sukulen dan berserat ini memberikan manfaat seperti buah yaitu pembersih gigi alamiah. Sifat membersihkan 
gigi secara alami pada buah dan sayur disebabkan karena meningkatnya air liur didalam mulut (Sariningsih, 2012).

Nilai rata-rata debris indeks pada responden sebelum mengkonsumsi buah siwalan adalah 1,13 dan sesudah mengkonsumsi buah siwalan menjadi 0,43 dengan penurunan nilai rata-rata debris indeks sebesar 0,7. Nilai rata-rata debris indeks sebelum mengkonsumsi nata de coco 1,1 dan sesudah mengkonsumsi nata de coco menjadi 0,6 dengan penurunan nilai rata-rata debris indeks sebesar 0,5.

Pada penelitian ini penurunan debris indeks dengan mengkonsumsi buah siwalan cenderung lebih tinggi dibandingkan dengan mengkonsumsi nata de coco, tetapi tidak terlalu signifikan dengan selisih rata-ratanya yaitu sebesar 0,2. Penurunan debris indeks pada saat mengkonsumsi buah siwalan lebih besar dibandingkan nata de coco, dikarenakan buah siwalan yang mengandung lebih banyak serat dan air sehingga cenderung lebih efektif sebagai pembersih gigi secara alami. Seperti pendapat Darmawan (2007) yang menyatakan bahwa penurunan angka debris indeks bisa dilakukan dengan mengkonsumsi aneka buah dan sayur yang mengandung serat. Aneka buah dan sayur merupakan asupan yang aman bagi gigi. Selain itu mengunyah buah dan sayur juga sangat baik untuk memberikan efek pemijat digusi dan menyegarkan aroma mulut.

\section{KESIMPULAN}

a. Nilai rata-rata DI sebelum mengkonsumsi buah siwalan adalah 1,13 dan nata de coco adalah 1,1 .

b. Nilai rata-rata DI sesudah mengkonsumsi buah siwalan adalah 0,43 dan sesudah mengkonsumsi nata de coco adalah 0,6.

c. Selisih DI sebelum dan sesudah mengkonsumsi buah siwalan adalah 0,7 sedangkan selisih DI sebelum dan sesudah mengkonsumsi nata de coco adalah 0,5. d. Buah siwalan lebih cenderung efektif menurunkan DI dibandingkan dengan nata de coco yaitu dengan selisih 0,2 .

\section{SARAN}

1. Bagi siswa dan masyarakat supaya mengkonsumsi buah yang banyak mengandung serat dan berair seperti buah siwalan dan nata de coco terutama setelah makan dapat sebagai pencuci mulut karena dapat mengurangi sisa-sisa makanan yang melekat pada permukaan gigi.

2. Bagi tenaga keperawatan gigi agar dapat memberikan informasi tentang efektivitas mengkonsumsi antara buah siwalan dan nata de coco dalam menurunkan debris indeks.

3. Dilakukan penelitian lanjutan dengan jenis buah yang berbeda terhadap debris indeks.

\section{DAFTAR PUSTAKA}

Arikunto, S.,2010,Prosedur Penelitian Satu Pendekatan Praktek, Rineka Cipta, Jakarta, Hal 65.

$$
\begin{aligned}
& \begin{array}{l}
\text { Ayudhita, } \\
\text { http://repository.usu.ac.id/bitstream/12 }
\end{array} \\
& \frac{\text { 3456789/23560/3/Chapter\%20II.pdf, }}{20 \text { April 2014. }}
\end{aligned}
$$

Darmawan, L.,2007, Cara Cepat Membuat Gigi Sehat dan Cantik Dengan Dental Cosmetics, Gramedia Pustaka Utama, Jakarta, Hal134-136.

Ghofur, A., 2012, Buku Pintar Kesehatan Gigi dan Mulut, Mitra Buku, Yogyakarta, Hal102.

Harmiawan, D., 2011, Memproduksi Nata De Coco Tanpa Limbah, http://ebookusaha-nata-decoco.com/, 14 April 2014. 
Herijulianti, E., Artini, S., Indriani,T.S., 2002, Pendidikan Kesehatan Gigi, Penerbit Buku Kedokteran ECG, Jakarta.

Lestari, I., Yanuwiadi, B., Soemarno 2013, Analisis Kesesuaian Vegetasi Lokal Untuk Ruang Terbuka Hijau Jalur Jalan di Pusat Kota Kupang, www.jpal.ub.ac.id/index.php/jpal/view /112, 23 April 2014.

Mangoenprasodjo,A.S.,2004,GigiSehatMulut Terjaga,Thinkfresh, Yogyakarta.

Notoatmodjo,

S., 2010, MetodologiPenelitianKesehatan, RhinekaCipta, Jakarta, Hal 60.

Pambayun, R., 2006, Teknologi Pengolahan Nata de Coco, Kanisius, Yogyakarta, Hal 11-13.

Pratiwi, D., 2007, Gigi SehatMerawat Gigi Sehari-hari, Kompas, Jakarta, Hal 31.

Riskesdas (RisetKesehatanDasar), 2007, Badan Penelitian dan Pengembangan Kesehatan, Kementrian Kesehatan RI, Jakarta.

Saragih, Y.P.,2004, MembuatNata De Coco,Puspa Wara, Jakarta.

Sariningsih, E., 2012, Merawat Gigi Anak Sejak Usia Dini, Gramedia, Jakarta, Hal 73,260.

Simorangkir,DS., 2010,Hubungan Pola Jajan Dengan Pengalaman Karies Murid Kelas VI SD Islam An Nizam,http://repository.usu.ac.id/bitstr eam/123456789/19567/5/Chapter\%20I .pdf, 17 Maret 2014.

Yunanto, D., 2011, Pengaruh Pemberian Nata De Coco Terhadap Kadar Kolestrol LDL Dan HDL Pada Tikus Hiperkolesterolemia, http://eprints.undip.ac.id/32602/, 23 April 2014.

Zumiati, S., 2009, Pewarna Nabati Makanan, Kanisius, Yogyakarta. 